\title{
Do Dual Tasks Have an Added Value Over Single Tasks for Balance Assessment in Fall Prevention Programs? A Mini-Review
}

\author{
A. Zijlstra ${ }^{a} \quad$ T. Ufkes $^{a} \quad$ D.A. Skelton ${ }^{b} \quad$ L. Lundin-Olsson ${ }^{c} \quad$ W. Zijlstra ${ }^{a}$ \\ ${ }^{a}$ Center for Human Movement Sciences, University Medical Center Groningen, University of Groningen, \\ Groningen, The Netherlands; ${ }^{b}$ School of Nursing, Midwifery and Social Work, University of Manchester, \\ Manchester, UK; ${ }^{c}$ Department of Community Medicine and Rehabilitation, Physiotherapy and \\ Geriatric Medicine, Umeå University, Umeå, Sweden
}

\section{Key Words}

Dual-task paradigm • Balance - Gait • Attention · Falls •

Geriatric assessment $\cdot$ Clinical evaluation

\begin{abstract}
Background: The Prevention of Falls Network Europe (ProFaNE) aims to bring together European researchers and clinicians to focus on the development of effective falls prevention programs for older people. One of the objectives is to identify suitable balance assessment tools. Assessment procedures that combine a balance task with a cognitive task may be relevant since part of all falls occurs during dualtask performance of walking or other balance activities. $\mathbf{O b}$ jective: To evaluate whether dual-task balance assessments are more sensitive than single balance tasks in predicting falls and detecting changes in balance performance after fall interventions. Methods: A systematic literature search was performed in the databases PubMed, EMBASE, CINAHL, AMED, PsycINFO and Cochrane. Articles were selected according to the following inclusion criteria: (1) population: older adults (mean age $\geq 65$ years), (2) assessment tool: dual task combining gait or other balance task with a cognitive task, (3) design: prospective or retrospective data collection of falls, or intervention study. Analysis of papers focused on measures of predictive ability or sensitivity-to-change for
\end{abstract}

both tasks during dual-task performance as well as for the single balance and cognitive task. Results: Out of 114 dualtask studies in older people, 19 articles matched the inclusion criteria. Fourteen studies had sample sizes of 60 subjects or less; the studied populations, task combinations as well as other methodological aspects varied. None of the articles reported the same statistical measures for both tasks during dual-task performance as well as single balance and cognitive task. In two studies with prospective data collection of falls, higher odds ratios were found for the dual compared to the single balance task. Conclusions: Upon the available literature, conclusions for an added value of dual balance tasks for fall prediction or assessing fall intervention effects cannot be made due to incomplete comparisons of single and dual balance tasks. Nevertheless, two studies do provide an indication that dual balance tasks may have added value for fall prediction.

Copyright $\odot 2008$ S. Karger AG, Basel

\section{Introduction}

Falling is a common problem in the growing population of older people. Approximately $30 \%$ of older adults experience a fall each year [1-3], and fall incidence is even higher (50\%) in women aged 85 and above [4]. The med-

\section{KARGER}

Fax +41613061234

E-Mail karger@karger.ch

www.karger.com
(C) 2008 S. Karger AG, Basel

0304-324X/08/0541-0040\$24.50/0

Accessible online at:

www.karger.com/ger
Dr. Wiebren Zijlstra

Center for Human Movement Sciences, University Medical Center Groningen University of Groningen, PO Box 196

NL-9700 AD Groningen (The Netherlands)

Tel. +31 50363 7868, Fax +31 50363 3150, E-Mail w.zijlstra@med.umcg.nl 
ical costs related to falls are substantial, e.g. fall-related injuries in people aged 60 years and over cost the United Kingdom government 981 million pounds in the year 2000 [5]. Falls often lead to a decreased quality of life when health, function and/or independence are impaired, and in some cases falls even lead to death [6]. In addition, falls can have psychological consequences such as fear of falling, which is associated with activity avoidance [7]. A reduction of physical activity may lead to further decline in functioning, and hence to further falls [8].

The Prevention of Falls Network Europe (ProFaNE) $[9,10]$ is a European Commission funded thematic network in which European researchers and clinicians are brought together to focus on the development of multifactorial prevention programs aimed at reducing the incidence of falls amongst older people. One of the objectives of the network is to identify balance assessment tools that can be used in the development of effective fall interventions. Balance assessment tools that target mobility impairment [11], e.g. abnormalities of balance and gait [11-13], may be useful for early detection of potential fallers who are eligible for inclusion in a fall prevention program, or for detecting changes in balance performance as a result of an intervention. The present study focuses on the relevance of assessment procedures that combine a balance task with a cognitive task.

Part of all falls in older people occurs during activities when attention needs to be divided between postural control and other tasks [14-16], such as when walking while maintaining a conversation. A possible explanation is that attention resources are limited [17] and postural control is more attention demanding in older adults than in young adults $[18,19]$. Also, older adults may prioritize tasks differently. In a study by Bloem et al. [20], older subjects seemed less inclined than younger subjects to use a 'posture first' strategy. This strategy consists of prioritizing balance maintenance (the 'primary' task) over the execution of a second task (e.g. manual or cognitive) [21], and thus can be considered as a 'safety first' strategy. Assessment methods incorporating dual-task paradigms appear to be helpful in revealing the effect of age or disease on the allocation of attention to postural tasks and may be sensitive in predicting fall risk and/or in evaluating outcomes of fall interventions in older people [19].

A literature review was performed to evaluate whether dual-task balance assessments have an 'added value' over single-task balance assessments. First, a systematic literature search was applied to collect studies in which balance performance of older people was assessed based on a dual-task approach, consisting of a gait or other balance task and a second cognitive task. Secondly, inclusion criteria were used to select all relevant studies for fall prediction or the evaluation of changes in balance performance. Finally, the methods and results of included papers were assessed based on criteria that need to be met for contrasting single- versus dual-task assessments.

\section{Methods}

\section{Search Methods}

A systematic literature search was conducted to obtain articles that use a dual-task paradigm to assess balance performance in older subjects. Articles were searched for in electronic databases PubMed, EMBASE, CINAHL, AMED, PsycINFO and Cochrane Central Register of Controlled Trials. The search strategy that was used in the PubMed database is summarized in scheme 1. Search strategies applied in the other databases were derived from the PubMed search, with the exception that the search in the EMBASE database was restricted to articles that were classified with the key term falling. The database search was conducted without language restrictions and limited to articles with publication dates to 2006. In addition, reference lists of relevant articles were hand-searched and a request to members of the ProFaNE was made to identify missing articles.

Scheme 1: Search strategy (summarized) used in the PubMed database. The bold terms are MeSH (Medical Subjects Headings) key terms.

(1) (gait OR walking OR locomotion OR musculoskeletal equilibrium OR posture)

(2) \#1 AND (aged OR aged, 80 and over OR aging)

(3) (cognition OR attention OR cognitive task(s) OR attention task(s) OR dual task(s) OR double task paradigm OR second task(s) OR secondary task(s)

(4) \#2 AND \#3

(5) \#4 AND humans

\section{Selection of Relevant Papers}

First, all studies using a dual-task paradigm, consisting of a gait or other balance task and a second cognitive task, were selected by screening abstracts and methods sections. Individual abstracts, review articles and studies evaluating sitting balance performance were excluded.

Second, only papers were included in which the dual-task paradigm was used (1) to predict future falls, (2) to discriminate between fallers versus non-fallers based on a retrospective data collection of falls, or (3) to detect changes in balance performance after an intervention. Studies were only included when the classification of fallers and non-fallers was based on actual fall events. Since a standardized fall definition is not available [22, 23], all fall definitions stated in the individual articles were accepted. The selection was limited to studies in which the mean age of the subject group(s) with older adults was 65 years or older. Articles that did not report results for dual-task balance performance were excluded as well as case studies, letters to the editor and studies that used a subjective scoring system to assess dual-task performance. No further exclusion criteria were used. 
Analysis of Relevant Papers

The following descriptive aspects were considered: study design (i.e. retrospective or prospective data collection of falls), number of subjects, selection criteria for the subject groups, classification of fallers, tasks and measures that were used to assess and report task performance, test order of tasks and follow-up period. Each article was assessed on whether the value for fall prediction or for detecting changes in balance performance of singleand dual-task balance assessments could be compared. For such a comparison, appropriate statistical measures for discriminative ability, predictive ability (i.e. sensitivity, specificity, predictive values, odds ratio, likelihood ratios) or sensitivity-to-change (e.g. standardized response mean (SRM)) need to be reported [24]. The same statistical measures should be reported for both tasks of the dual task as well as for the single balance and cognitive tasks. The effects of adding a cognitive task to the balance task may remain covert when only balance task performance is analyzed, as dualtask interference effects can be shown by a deterioration in performance on the balance task, cognitive task, or both tasks, depending on which task is prioritized.

\section{Results}

The searches in databases PubMed, EMBASE, CINAHL, AMED, PsycINFO and Cochrane resulted in $305,203,175,27,51$ and 15 references, respectively. After removing duplicate references, a total of 606 articles were obtained. 114 studies were identified which used a dualtask approach, consisting of a gait or other balance task combined with a second cognitive task, to assess balance performance in older subjects ${ }^{1}$. Categorized according to study design, table 1 summarizes the 19 articles that met the inclusion criteria. The article by Verghese et al. [25] includes results based on a retrospective as well as prospective data collection of falls. The two articles by Ashburn et al. [26,27] describe results of the same population of older Parkinson's disease patients using a retrospective and prospective data collection of falls respectively.

The selection criteria for population samples varied between studies. Eight studies exclusively included community-dwelling older persons [25-32]. Two studies also included institutionalized older persons [33,34], while Springer et al. [35], Lundin-Olsson et al. [36] and Camicioli and Licis [37] limited the study population to institutionalized older adults. The remaining articles did not mention details on whether or not (part of) subjects were institutionalized. Seven studies exclusively included old-

\footnotetext{
1 References of the 114 dual-task studies and an overview in which the studies and cognitive tasks used are categorized by population and balance task (i.e. gait or other balance task), will be provided to the interested reader after a request to the corresponding author.
}

er people with a specific pathology or medical condition, namely Parkinson's disease patients [26, 27, 38], patients with Alzheimer's disease [37] or stroke [29, 39], and persons with unilateral lower limb amputation [40]. Twelve of the 19 studies gave information about excluding persons with specific medical conditions. Lundin-Olsson et al. [36] reported that part of the subjects was diagnosed with dementia, previous stroke and/or depression, and Verghese et al. [25] reported neuropathy in $20 \%$ of the subjects and previous stroke in $3 \%$. The other studies did not give clear information on whether subjects had (additional) medical conditions.

Table 2 shows the results of articles which report measures for discriminative or predictive value for falls of single and/or dual tasks. The three intervention studies did not present measures for sensitivity-to-change. Appropriate measures for discriminative ability of the dual task(s) were mentioned for 3 of 10 evaluations with a retrospective data collection of falls. In most cases, sensitivity, specificity and predictive values were high (i.e. $\geq 80 \%$ ). In the study of Dibble and Lange [38], a low sensitivity (i.e. $\leq 54 \%$ ) was obtained when using an a priori cut-off score. Measures indicating the predictive value of the dual task(s) were reported in 5 of 7 evaluations with a prospective data collection of falls. In most cases, specificity and predictive values were moderate (i.e. 55-79\%) or high whereas sensitivity was low.

None of the 19 articles presented the same statistical measures for both tasks during dual-task performance as well for the single balance and cognitive task. The articles of Shumway-Cook et al. [31] and Dibble and Lange [38] did report measures for discriminative ability for both single and dual balance task. Also, two articles with prospective data collection of falls (i.e. Ashburn et al. [27] and Verghese et al. [25]) reported appropriate statistical measures for both single and dual balance tasks. In addition, Bergland and Wyller [28] reported that one of the dual-task conditions gave the best predictive value for $\mathrm{fu}$ ture falls with an odds ratio of 2.4. However, they did not mention the odds ratios for the other single- and dualtask conditions. All the above-mentioned articles did not report statistical measures for cognitive task performance.

\section{Discussion}

A literature review was performed to evaluate whether dual-task balance assessments have an 'added value' over single-task balance assessments for fall prevention, i.e. 
Table 1. Overview of descriptive information on included articles using a dual-task balance assessment. Mean age (range), years, is indicated

\begin{tabular}{|c|c|c|c|}
\hline \multicolumn{3}{|r|}{ Study population } & Tasks, test conditions and measures \\
\hline 1 & $\begin{array}{l}\text { Shumway-Cook } \\
\text { et al. } \\
1997[21]\end{array}$ & $\begin{array}{l}20 \text { young adults (age } 31 \text { (24-44), } 50 \% \text { female), } 20 \text { older non-fallers } \\
\text { (age } 74(65-86), 55 \% \text { female), } 20 \text { older fallers (age } 78(65-94) \text {, } \\
65 \% \text { female). } \\
\text { Fallers had a self-report of two or more falls in the previous } \\
6 \text { months in the absence of a known neurological or musculoskeletal } \\
\text { diagnosis. }\end{array}$ & $\begin{array}{l}\text { Balance tasks } \\
\text { Standing on force platform. Two surface conditions, } \\
\text { firm vs. compliant. Measure of postural sway. } \\
\text { Cognitive tasks } \\
\text { Sentence Completion (SC) and Judgment of Line } \\
\text { Orientation (JOLO). Speed (2) and accuracy (2) measures. } \\
\text { The order of tasks was randomized. }\end{array}$ \\
\hline 2 & $\begin{array}{l}\text { Shumway-Cook } \\
\text { et al. } \\
2000[31]\end{array}$ & $\begin{array}{l}\text { Community-dwellers: } 15 \text { older non-fallers (age } 78 \text { (65-85), } \\
67 \% \text { female), } 15 \text { older fallers (age } 86 \text { ( } 76-95), 53 \% \text { female). Fallers } \\
\text { had a self-report of two or more falls in the previous } 6 \text { months in the } \\
\text { absence of a known neurological or musculoskeletal diagnosis. } \\
\text { Fall definition: any event that led to an unplanned, unexpected contact } \\
\text { with a supporting surface, excluding falls resulting from unavoidable } \\
\text { environmental hazards. }\end{array}$ & $\begin{array}{l}\text { Balance task } \\
\text { Timed Up and Go test (TUG). Speed measure. } \\
\text { Cognitive task } \\
\text { Counting backwards by threes. The order of tasks was } \\
\text { randomized. }\end{array}$ \\
\hline 4 & $\begin{array}{l}\text { Ashburn et al. } \\
2001[26]\end{array}$ & $\begin{array}{l}\text { Community-dwelling older Parkinson's disease patients: } 19 \text { non-fallers, } \\
29 \text { fallers. } \\
\text { Fallers: self-report of one or more falls in the previous } 12 \text { months. } \\
\text { Fall definition: event which results in a person coming to rest } \\
\text { unintentionally on the ground or other level, not the result of a major } \\
\text { intrinsic event or overwhelming hazard. } \\
\text { Selection criteria: no other neurological or vestibular conditions and } \\
\text { no gross cognitive impairment. }\end{array}$ & $\begin{array}{l}\text { Balance task } \\
\text { Standing on foot plates. Measure of postural sway. } \\
\text { Cognitive task } \\
\text { Make simple color judgment on a series of playing cards. }\end{array}$ \\
\hline 5 & $\begin{array}{l}\text { Lajoie and } \\
\text { Gallagher } \\
2004[34]\end{array}$ & $\begin{array}{l}80 \text { older non-fallers (age } 74,64 \% \text { female), } 45 \text { older fallers (age } 76, \\
78 \% \text { female). Selected within the community, from nursing homes } \\
\text { and senior residences. } \\
\text { Fallers had one or more falls during the past year. } \\
\text { Fall definition: according to Kellogg Group [14]. } \\
\text { Exclusion criteria fallers: neurological disorder. }\end{array}$ & $\begin{array}{l}\text { Balance task } \\
\text { Standing on force platform. Measure of postural sway. } \\
\text { Cognitive task } \\
\text { Simple Reaction Time (RT) task: respond verbally to } \\
\text { auditory stimulus. Speed measure. }\end{array}$ \\
\hline 7 & $\begin{array}{l}\text { Hyndman et al. } \\
2006 \text { [29] }\end{array}$ & $\begin{array}{l}36 \text { community-dwelling older people with stroke (age } 67,42 \% \text { female); } \\
10 \text { fallers, } 26 \text { non-fallers. } \\
\text { Exclusion criteria: other neurological or musculoskeletal conditions } \\
\text { likely to affect balance, syncope, psychiatric disorders, receptive aphasia } \\
\text { or uncorrected visual or hearing impairments. }\end{array}$ & $\begin{array}{l}\text { Balance tasks } \\
\text { Standing on force platform ( } 2 \text { measures of postural sway), } \\
\text { walking } 5 \mathrm{~m} \text { at a comfortable pace (speed measure and } 2 \text { gait } \\
\text { measures). } \\
\text { Cognitive task } \\
\text { Auditory mental task: remembering a shopping list. } \\
\text { Accuracy measure. The order of trials was randomized. }\end{array}$ \\
\hline 8 & $\begin{array}{l}\text { Springer et al. } \\
2006 \text { [35] }\end{array}$ & $\begin{array}{l}19 \text { young adults (age 29), } 24 \text { older non-fallers (age } 71 \text { ) and } 17 \text { older } \\
\text { fallers (age } 76 \text { ). Older adults were from community-centers. } \\
\text { Fallers had a self-report of one or more falls, of unknown origin, } \\
\text { in the previous } 6 \text { months. All fallers reported two or more falls in the } \\
\text { previous year. } \\
\text { Exclusion criteria: major depression, cognitive decline, neurological, } \\
\text { affective, orthopedic or other co-morbidities likely to impact gait. }\end{array}$ & $\begin{array}{l}\text { Balance task } \\
\text { Walking up and down a } 25 \text {-meter long hallway for } 2 \text { min. } \\
\text { Gait measures (3). } \\
\text { Cognitive tasks } \\
\text { Simple task, complex task and arithmetic task. Simple and } \\
\text { complex task: listening to a text, answering } 10 \text { multiple- } \\
\text { choice questions regarding the content of the text after the } \\
\text { walk. The complex task also consisted of phoneme } \\
\text { monitoring. Arithmetic task: serial subtractions of } 7 \text {, } \\
\text { starting from 500. Accuracy measures (4). } \\
\text { The tasks were performed in a standardized order. }\end{array}$ \\
\hline
\end{tabular}


Table 1 (continued)

\begin{tabular}{|c|c|c|c|}
\hline & Article & Study population & Tasks, test conditions and measures \\
\hline 9 & $\begin{array}{l}\text { Vaillant et al. } \\
2006[32]\end{array}$ & $\begin{array}{l}95 \text { community-dwelling older women with osteoporosis (age } 73 \text { ); } \\
25 \text { fallers, } 70 \text { non-fallers. } \\
\text { Fallers had a self-report of one or more falls during the previous } \\
12 \text { months. }\end{array}$ & $\begin{array}{l}\text { Balance tasks } \\
\text { Timed Up and Go (speed measure), One Leg Balance test } \\
\text { with left and right leg (time measure). } \\
\text { Cognitive task } \\
\text { Subtraction by two's, subtraction by fives or addition by } \\
\text { threes. The order of tasks was randomized. }\end{array}$ \\
\hline & Article & Study population and follow-up period & Tasks, test conditions, measures \\
\hline
\end{tabular}

Studies with a prospective data collection of falls: prediction of future falls or fall related injury

10 Lundin-Olsson 58 institutionalized older adults (age 80, 72\% female, dementia et al. $\quad(n=26)$, depression $(n=25)$, previous stroke $(n=20))$. Falls indoors 1997 [36] recorded during a 6-month follow-up period (registered by staff): 21 fallers (one or more falls).

11 Ashburn et al. Community-dwelling Parkinson's disease patients. Follow-up period 2001 [27] of 3 months, in which falls recorded (phone interviews): 35 older non-fallers, 22 older fallers.

Fall definition: event which results in a person coming to rest unintentionally on the ground or other lower level, not as the result of a major intrinsic event or overwhelming hazard.

Selection criteria: scored above 8 on the Middlesex Assessment of Mental State, no other neurological or vestibular conditions.

12 Verghese et al. Non-demented community-dwellers (age 80, 57\% female, 20\% 2002 [25] neuropathy, $3 \%$ previous stroke). Falls in the previous year were obtained at baseline: 43 older non-fallers (age 79, 56\% female), 17 older fallers (age 82, 59\% female).

Follow-up period of 12 months, in which falls recorded (structured phone interviews): 46 older non-fallers (age 80, 54\% female), 13 older fallers (age 79, 69\% female).

Fall definition: sudden, unintentional, unprovoked changes in body posture resulting in the person being on a lower level, not due to a major intrinsic event (stroke) or an overwhelming hazard.

13 Bootsma-van- Older adults all aged 85 at baseline (65\% female). Follow-up period der-Wiel et al. of 12 months, in which falls recorded (standardized questionnaire): 2003 [41]
Normal walking with social interaction. Observed was whether subjects stopped walking when a conversation was started.

\section{Balance task}

Standing on foot plates. Measure of postural sway.

Cognitive task

Make simple color judgment on a series of playing cards. recurrent falls ( $\mathrm{n}=71,63 \%$ female).

Balance task

Walk $20 \mathrm{ft}$ and back (total of $40 \mathrm{ft}$ ) at a normal walking pace. Speed measure.

Cognitive tasks

Reciting letters of the alphabet and reciting alternate letters

of the alphabet. The order of the dual tasks was randomized.

Balance task

Walk as quickly as possible back and forth along a 3-meter

line, for a total of $12 \mathrm{~m}$ and 3 turns of $180^{\circ}$. Gait measures (2). Cognitive task

Verbal fluency: recite as many names as possible of animals or professions. Speed measure. The dual task was performed after the single tasks.

\footnotetext{
14 Bergland and 307 community-dwellers (age 81 (75-93), all women). Registration Wyller of falls resulting in serious fall related injury by fall calendar during a 2004 [28] 12-month follow-up period.

Fall definition: according to Kellogg Group [14].

Serious fall related injuries: fractures dislocations, head injuries resulting in loss of consciousness, other injuries resulting in medical care. Exclusion criteria: major cognitive impairment.

15 Camicioli and Patients from Alzheimer Care Units. Follow-up period of 12 months Licis in which falls recorded (bimonthly chart reviews): 24 older non-fallers 2004 [37] in which falls recorded (bimonthly chart reviews): 24 older non
(age 82, 92\% women), 18 older fallers (age 83, 78\% women). Fallers had one or more falls during the follow-up period. Fall definition: event that resulted in a person coming to rest unintentionally on the ground or other lower level and other than a consequence of a major intrinsic event.

16 Hyndman and 63 older adults with recent stroke, not cognitively impaired Ashburn (age 68 (42-84), 43\% women). Follow-up period of 6 months in 2004 [39] which falls recorded (falls diary and 2-weekly follow-up phone calls): 33 non-fallers, 15 one time fallers, 15 repeat fallers. Fall definition: an event that results in a person coming to rest unintentionally on the ground or other lower level, not as a result of a major intrinsic event or overwhelming hazard.

Selection criteria: no other neurological conditions and no acute medical or musculoskeletal conditions impeding mobility or balance.
}

Balance task

Standing on force platform. Two conditions, eyes open fixed at target vs. blindfolded. Measures of postural sway. Cognitive tasks

Checking whether simple calculations were correct and Stroop's colored words test. The tasks were always performed in the same order.

\section{Balance task}

Cognitive task

Count from one upward by ones. Fixed task order.

Normal walking with social interaction. Observed was whether subjects stopped walking for at least one second during conversation.
Walking on a foot mat. Gait measures (10). 
Table 1 (continued)

Article Study population Intervention, tasks, test conditions, measures

Intervention studies: evaluating change in balance performance

17 Geurts et al. Eight persons with recent unilateral lower limb amputation 1991 [40] (age 68 (25-84), 30\% women), 8 healthy controls matched for age (66) and gender.

Exclusion criteria: serious cognitive dysfunctions.

Balance task

Standing on force platform. Measures of postural sway (2).

Cognitive task

Modified Stroop test or subtract the number 3 from an

arbitrary starting number between 50 and 100 .

Speed ( 1 = and accuracy ( 1$)$ measures.

Patients were tested at the start and the end of rehabilitation on all tasks. Controls were measured once.

18 Lindemann 47 ambulatory community-dwellers (age 73, 92\% female).

Intervention

Thai Chi-Qigong lessons, $1 \mathrm{~h}$ once a week for 12 weeks. Balance task

Standing on force platform. Two conditions, eyes open (EO)

vs. eyes closed (EC). Measures of postural sway (2).

Cognitive task

Silent memory task (first item Alzheimer's disease

assessment scale). Showed 10 terms, read out loudly and

memorize. At the end, repeat as many terms as possible.

Accuracy measures (3). Pre- and post-testing single balance

tasks and dual-task EO.

19 Lajoie $2004[33]$
Community-dwellers and people from residential care facilities:

12 control subjects (age 71, 83\% female), 12 training group participants (age $70,83 \%$ female).

Exclusion criteria: diabetes, neurological or sensory disorders, recurrent dizziness or unsteadiness, use of medications that may effect balance, joint replacement, medical conditions interfering with daily activities.
Intervention

Computerized balance training: stand on force platform and visualize displacement of center of pressure (COP) by means

of monitor in front. Reference given by rectangle and red cursor representing COP.

Asked to position cursor in centre of rectangle. 16 sessions of $1 \mathrm{~h}$ over an 8-week period.

Training session $=15$ trials of 1 min. Feedback fading protocol.

Balance task

Standing on force platform. Measure of postural sway. Cognitive task

Probe Reaction Time (RT): say 'top' as fast as possible after hearing a 'beep'. Speed measure. Pre- and post-testing dual task, retention test 2 weeks after post-testing in training group participants.

$\mathrm{n}=$ Number of subjects

whether they are more sensitive in predicting falls and detecting changes in balance performance after a fall intervention. Despite a broad search, some studies that are relevant for this review may have been overlooked. For example, relevant articles in the EMBASE database that are not labeled with the key term falling were not identified and neither were studies published in 2006 that were added to the databases after March 15, 2007.

The structured search yielded 114 papers that report on task performance of older people during the combination of a gait or other balance task and a cognitive task. Only 19 of these articles were in line with the scope of this review. Because of the small number of available relevant papers, no methodological selection criteria were used. As a result, the included studies are heterogeneous.

\section{Descriptive Aspects}

Fourteen of the 19 papers presented results of relatively small studies with subject numbers of 60 or less. The studies with prospective data collection of falls by Bootsma-van der Wiel et al. (380 subjects) [41] and Bergland and Wyller (307 subjects) [28] are clear positive exceptions in this respect. Data of the available studies are difficult to pool because of the variance in methodological aspects. The characteristics of the studied populations varied due to diverse selection criteria and there are differences in the classification of fallers. Variety also existed in the task combinations that were applied. Balance tasks differed from quiet stance under diverse testing conditions, to walking, to performing the timed up and go or one leg balance test; studies used a counting, sentence completion, reaction time, verbal fluency task or 
Table 2. Results of the eight dual-task studies which present measures for the discriminative or predictive value for falls

\begin{tabular}{|c|c|c|c|c|c|c|c|c|}
\hline Article & \multicolumn{3}{|c|}{ Retrospective data collection of falls } & \multicolumn{5}{|c|}{ Prospective data collection of falls } \\
\hline \multicolumn{9}{|l|}{ Sensitivity, \% } \\
\hline Single-task balance & $87 / 80^{*}$ & & $39^{\mathrm{a}} / 93^{\mathrm{b}}$ & & & 38 & & \\
\hline Dual-task balance & $80 / 80^{*}$ & & $35^{\mathrm{a}} / 93^{\mathrm{b}}$ & 48 & & $46 / 39$ & & $53^{\mathrm{A}} / 73^{\mathrm{R}}$ \\
\hline Dual-task cognitive & & 83 & & & & & & \\
\hline \multicolumn{9}{|l|}{ Specificity, \% } \\
\hline Single-task balance & $87 / 100^{*}$ & & $87^{\mathrm{a}} / 30^{\mathrm{b}}$ & & & 85 & & \\
\hline Dual-task balance & $93 / 93^{*}$ & & $96^{\mathrm{a}} / 35^{\mathrm{b}}$ & 95 & & $89 / 96$ & & $70^{\mathrm{A}} / 69^{\mathrm{R}}$ \\
\hline Single-task cognitive & & & & & & & & \\
\hline Dual-task cognitive & & 87 & & & & & & \\
\hline \multicolumn{9}{|l|}{ Single-task balance } \\
\hline Dual-task balance & & & & 76 & & & & $62^{\mathrm{A}} / 89^{\mathrm{R}}$ \\
\hline \multicolumn{9}{|l|}{ Odds ratio } \\
\hline Single-task balance & & & $0.3^{-} / 1.3^{+, \mathrm{b}}$ & & 1.1 & 4.3 & & \\
\hline Dual-task balance & & & $0.2^{-} / 1.4^{+, \mathrm{b}}$ & & 1.1 & 7.0/13.7 & 2.4 & \\
\hline $\begin{array}{l}\mathrm{A} / \mathrm{R}=\text { All fallers/rep } \\
\text { value. } \\
{ }^{*} \text { Calculated with the } \\
{ }^{\mathrm{a}} \text { Calculated using cu } \\
{ }^{\mathrm{b}} \text { Calculated with the } \\
{ }^{\mathrm{c}} \text { Overall predictive }\end{array}$ & $\begin{array}{l}\text { llers; }{ }^{+/-}=\mathrm{pc} \\
\text { of maximiz } \\
\text { scores repor } \\
\text { of maximizi } \\
(\%) \text {. }\end{array}$ & $\begin{array}{l}\text { sitive/negati } \\
\text { ing sensitivit } \\
\text { ted in previo } \\
\text { ng sensitivit }\end{array}$ & $\begin{array}{l}\text { ve likelihooc } \\
\text { y, specificity } \\
\text { us research. } \\
\text { y and minim }\end{array}$ & $\begin{array}{l}\text { tio; } P P V=p \\
\text { d predicted } 1 \\
\text { ng the negat }\end{array}$ & $\begin{array}{l}\text { sitive predic } \\
\text { ve likelihood }\end{array}$ & tive value; $N$ & $\mathrm{PV}=$ negati & ve predictive \\
\hline
\end{tabular}

another cognitive task. In addition, the measures that are needed to assess and report task performance differed. For example, studies used diverse kinetic, electromyographic, force plate and gait measures to assess balance performance. Different follow-up times were applied and the studies varied in whether or not the order of tasks was randomized.

Value of Dual-Task Balance Assessments Compared to Single-Task Assessments

None of the 19 articles reported results in a way that allowed for a complete comparison between single and dual balance task. For a full comparison, the same statistical measure indicating the value for fall prediction or detecting changes in balance performance needs to be reported for both tasks of the dual task as well as the single balance and cognitive task. Twelve evaluations did not report measures for sensitivity-to-change, discriminative or predictive ability.
In two studies with retrospective data collection of falls [31,38], prediction numbers were reported for dual and single balance task. Results for single and dual balance tasks were similar in both studies. However, these results do not yet provide sufficient evidence to conclude that single and dual balance tasks have similar value for discriminating between fallers and non-fallers, since performances on the cognitive task were not taken into account. Subjects that have difficulty with multiple tasking may have prioritized performance on the balance task and accepted a decline on the cognitive task. The results of Condron and Hill [42] provide an indication that a dual task may have added value over the single balance task for classifying older adults into healthy adults versus adults with mild increase in fall risk. One of the task conditions in which standing on a force platform was combined with a counting task showed the highest discriminative ability compared to the single balance task with prediction numbers of $80 \%$. However, the results of the 
study do not provide any indications on the predictive value for future falls since fall events were collected retrospectively.

Two studies with prospective data collection of falls $[25,27]$ reported prediction numbers for both single balance and dual balance tasks. Ashburn et al. [27] mentioned similar odds ratios, whereas Verghese et al. [25] reported higher odds ratios for dual balance task performance compared to single balance task performance. In addition, Bergland and Wyller [28] reported that one of the dual-task conditions gave the best predictive value for future falls with an odds ratio of 2.4. The results by Bergland and Wyller [28] and some of the results by Verghese et al. [25] provide some indications for an added value of the dual balance task over the single balance task for fall prediction. Nevertheless, concluding statements on whether or not dual balance task assessments are more sensitive for fall prediction or for detecting changes in balance performance after fall prevention programs cannot be made, since none of the available relevant dual-task studies give a full report of appropriate statistical measures for sensitivity-to-change, discriminative or predictive value related to falls of single and dual tasks.

\section{Assessment Profile}

The low sensitivity (i.e. $<55 \%$ ) reported for fall prediction (see table 2) indicates that only a part of all fallers were indentified by the dual-task assessment. The dualtask approach may therefore be useful only for identifying fallers that have increased attention demands of postural control. Other subgroups of fallers may be identified by targeting other possible risk factors for falls. An assessment profile consisting of divergent assessments targeting different risk factors (e.g. see Lord et al. [43]), including a dual-task assessment, may be more predictive of falls than a single assessment. The different subgroups of fallers that are identified by such an assessment profile can subsequently be targeted with a specific intervention (e.g. strength or power training, balance training, improving sensory functioning, cognitive training, reducing fear of falling, dual-task training [44-46]).

\section{Implications for Future Studies}

The results of this review clearly indicate that it is of utmost importance to report measures of discriminative, predictive ability or sensitivity-to-change when balance assessments are used for fall prediction or detecting changes in balance performance after an intervention. In addition, this review indicates that, in the context of fall prevention programs, evaluations of dual versus single balance tasks need to consider a number of issues. As described in the preceding sentences and the methods section of this paper, studies need to report appropriate statistical measures for both tasks of the dual-task assessment and for the matching single balance and cognitive tasks. Future studies can also investigate whether an overall performance score that combines the scores on the cognitive and balance task (e.g. see Lindemann et al. [30]) is more sensitive for predicting falls or detecting changes in balance performance than the individual balance or cognitive task score during dual-task performance. Future studies should preferably have large sample sizes. The majority of the included studies in this review only had sample sizes of 60 subjects or less. To allow for data pooling, future studies need to standardize relevant methodological aspects, e.g. inclusion and exclusion criteria for subjects, classification of fallers, the specific tasks and measures, task order and follow-up time. A standardization of dual balance task assessments requires further knowledge of the performance on specific dual balance tasks in different older populations. It is likely that balance assessments in different subpopulations of older people (e.g. institutionalized, communitydwelling older people or older people with a specific pathology) require different task combinations, since both motor and cognitive functioning vary in these subpopulations. Also, task combinations that discriminate between known fallers and non-fallers do not necessarily have to be suitable for fall prediction or be sensitive to changes in balance performance after a fall prevention program. Future studies should use a prospective data collection of falls when assessing the predictive value of dual-task balance assessments. Most of the included studies in this review used a retrospective data collection of falls. Studies with retrospective data collection are more easily performed, but can only give indications of which task combination(s) may be suitable for fall prediction. Lastly, future studies should preferably also include additional (validated) tests that assess different aspects of sensory-motor functioning, balance and mobility. Thus, dual-task balance performance can be assessed in relation to relevant sensory-motor aspects (e.g. muscle force, sensory function) and other validated balance tests in order to find out whether single or combined assessments are more predictive of falls or more sensitive to detecting changes in balance performance than the dual-task paradigm alone. 


\section{Acknowledgements}

The authors are participants in the ProFaNE thematic network, which is a project in Key Action \#6 (The Ageing Population and their Disabilities), part of the European Commission's Fifth Framework, Quality of Life and Management of Living Resources
Program, funded by the European Commission (QLRT-200102705). The content of the manuscript does not represent the opinion of the European Community, and the Community is not responsible for any use that might be made of the information presented in the text.

\section{References}

1 Berg WP, Alessio HM, Mills EM, Tong C: Circumstances and consequences of falls in independent community-dwelling older adults. Age Ageing 1997;26:261-268.

$\longrightarrow 2$ Gill T, Taylor AW, Pengelly A: A populationbased survey of factors relating to the prevalence of falls in older people. Gerontology 2005;51:340-345.

3 Hausdorff JM, Rios DA, Edelberg HK: Gait variability and fall risk in community-living older adults: a 1-year prospective study. Arch Phys Med Rehabil 2001;82:1050-1056.

-4 Blake AJ, Morgan K, Bendall MJ, Dallosso H, Ebrahim SB, Arie TH, Fentem PH, Bassey EJ: Falls by elderly people at home: prevalence and associated factors. Age Ageing 1988;17: 365-372.

5 Scuffham P, Chaplin S, Legood R: Incidence and costs of unintentional falls in older people in the United Kingdom. J Epidemiol Community Health 2003;57:740-744.

-6 Minino AM, Anderson RN, Fingerhut LA, Boudreault MA, Warner M: Deaths: injuries, 2002. Natl Vital Stat Rep 2006;54:1-124.

7 Yardley L, Smith H: A prospective study of the relationship between feared consequences of falling and avoidance of activity in community-living older people. Gerontologist 2002;42:17-23.

$\checkmark 8$ Spano A, Forstl H: Falling and the fear of it. Int J Geriatr Psychiatry 1992;7:149-151.

9 Prevention of Falls Network Europe. Available at http://www.profane.eu.org. 2007.

-10 Skelton DA, Becker C, Lamb SE, Close JCT, Zijlstra W, Yardley L, Todd CJ: Prevention of Falls Network Europe: a thematic network aimed at introducing good practice in effective falls prevention across Europe. Eur J Ageing 2004;1:89-94.

- 11 Graafmans WC, Ooms ME, Hofstee HM, Bezemer PD, Bouter LM, Lips P: Falls in the elderly: a prospective study of risk factors and risk profiles. Am J Epidemiol 1996;143: 1129-1136.

-12 Nevitt MC, Cummings SR, Kidd S, Black D: Risk factors for recurrent nonsyncopal falls. A prospective study. JAMA 1989;261:26632668.

-13 Tinetti ME, Speechley M, Ginter SF: Risk factors for falls among elderly persons living in the community. N Engl J Med 1988;319: 1701-1707.
14 The prevention of falls in later life. A report of the Kellogg International Work Group on the Prevention of Falls by the Elderly. Dan Med Bull 1987;34(suppl 4):1-24.

15 Bergland A, Pettersen AM, Laake K: Falls reported among elderly Norwegians living at home. Physiother Res Int 1998;3:164-174.

- 16 Milisen K, Detroch E, Bellens K, Braes T, Dierickx K, Smeulders W, Teughels S, Dejaeger E, Boonen S, Pelemans W: Falls among community-dwelling elderly: a pilot study of prevalence, circumstances and consequences in Flanders (in Dutch). Tijdschr Gerontol Geriatr 2004;35:15-20.

17 Shumway-Cook A, Woollacott M: Attentional demands and postural control: the effect of sensory context. J Gerontol A Biol Sci Med Sci 2000;55:M10-M16.

18 Lajoie Y, Teasdale N, Bard C, Fleury M: Attentional demands for static and dynamic equilibrium. Exp Brain Res 1993;97:139144.

19 Woollacott M, Shumway-Cook A: Attention and the control of posture and gait: a review of an emerging area of research. Gait Posture 2002;16:1-14.

-20 Bloem BR, Valkenburg VV, Slabbekoorn M, Willemsen MD: The Multiple Tasks Test: development and normal strategies. Gait Posture 2001;14:191-202.

21 Shumway-Cook A, Woollacott M, Kerns KA, Baldwin M: The effects of two types of cognitive tasks on postural stability in older adults with and without a history of falls. J Gerontol A Biol Sci Med Sci 1997;52:M232-M240.

22 Hauer K, Lamb SE, Jorstad EC, Todd C, Becker C: Systematic review of definitions and methods of measuring falls in randomised controlled fall prevention trials. Age Ageing 2006;35:5-10.

23 Zecevic AA, Salmoni AW, Speechley M, Vandervoort AA: Defining a fall and reasons for falling: comparisons among the views of seniors, health care providers, and the research literature. Gerontologist 2006;46: 367-376.

24 Moe-Nilssen R, Nordin E, Lundin-Olsson L: Criteria for evaluation of measurement properties of clinical balance measures for use in fall prevention studies. J Eval Clin Pract 2008;14:236-240.
25 Verghese J, Buschke H, Viola L, Katz M, Hall C, Kuslansky G, Lipton R: Validity of divided attention tasks in predicting falls in older individuals: a preliminary study. J Am Geriatr Soc 2002;50:1572-1576.

26 Ashburn A, Stack E, Pickering RM, Ward CD: A community-dwelling sample of people with Parkinson's disease: characteristics of fallers and non-fallers. Age Ageing 2001; 30:47-52.

27 Ashburn A, Stack E, Pickering RM, Ward CD: Predicting fallers in a community-based sample of people with Parkinson's disease. Gerontology 2001;47:277-281.

28 Bergland A, Wyller TB: Risk factors for serious fall related injury in elderly women living at home. Inj Prev 2004;10:308-313.

29 Hyndman D, Ashburn A, Yardley L, Stack E: Interference between balance, gait and cognitive task performance among people with stroke living in the community. Disabil Rehabil 2006;28:849-856.

30 Lindemann U, Hammer W, Muche R, Nikolaus TH, Becker C: Postural control in the elderly: effect of a twelve-week Tai ChiQigong intervention in healthy elderly. Eur J Geriatr 2003;5:182-186.

31 Shumway-Cook A, Brauer S, Woollacott M: Predicting the probability for falls in community-dwelling older adults using the Timed Up and Go Test. Phys Ther 2000;80: 896-903.

32 Vaillant J, Martigne P, Vuillerme N, CaillatMiousse JL, Parisot J, Juvin R, Nougier V: Prediction of falls with performance on Timed 'Up-and-Go' and one-leg-balance tests and additional cognitive tasks (in French). Ann Readapt Med Phys 2006;49: $1-7$.

33 Lajoie Y: Effect of computerized feedback postural training on posture and attentional demands in older adults. Aging Clin Exp Res 2004;16:363-368.

34 Lajoie Y, Gallagher SP: Predicting falls within the elderly community: comparison of postural sway, reaction time, the Berg balance scale and the Activities-specific Balance Confidence (ABC) scale for comparing fallers and non-fallers. Arch Gerontol Geriatr 2004;38:11-26.

- 35 Springer S, Giladi N, Peretz C, Yogev G, Simon ES, Hausdorff JM: Dual-tasking effects on gait variability: the role of aging, falls, and executive function. Mov Disord 2006;21: 950-957. 
-36 Lundin-Olsson L, Nyberg L, Gustafson Y: 'Stops walking when talking' as a predictor of falls in elderly people. Lancet 1997;349: 617.

-37 Camicioli R, Licis L: Motor impairment predicts falls in specialized Alzheimer care units. Alzheimer Dis Assoc Disord 2004;18: 214-218.

38 Dibble LE, Lange M: Predicting falls in individuals with Parkinson disease: a reconsideration of clinical balance measures. J Neurol Phys Ther 2006;30:60-67.

39 Hyndman D, Ashburn A: Stops walking when talking as a predictor of falls in people with stroke living in the community. J Neurol Neurosurg Psychiatry 2004;75:994-997.
40 Geurts AC, Mulder TW, Nienhuis B, Rijken RA: Dual-task assessment of reorganization of postural control in persons with lower limb amputation. Arch Phys Med Rehabil 1991;72:1059-1064.

41 Bootsma-van-der-Wiel A, Gussekloo J, de Craen AJM, van Exel E, Bloem BR, Westendorp RGJ: Walking and talking as predictors of falls in the general population: The Leiden 85-Plus Study. J Am Geriatr Soc 2003;51: 1466-1471.

42 Condron JE, Hill KD: Reliability and validity of a dual-task force platform assessment of balance performance: effect of age, balance impairment, and cognitive task. J Am Geriatr Soc 2002;50:157-162.

43 Lord SR, Menz HB, Tiedemann A: A physiological profile approach to falls risk assessment and prevention. Phys Ther 2003;83: 237-252.
44 Dault MC, Frank JS: Does practice modify the relationship between postural control and the execution of a secondary task in young and older individuals? Gerontology 2004;50:157-164.

45 Roerdink M, De HM, Daffertshofer A, Donker SF, Geurts AC, Beek PJ: Dynamical structure of center-of-pressure trajectories in patients recovering from stroke. Exp Brain Res 2006;174:256-269.

46 Silsupadol P, Siu KC, Shumway-Cook A, Woollacott $\mathrm{MH}$ : Training of balance under single- and dual-task conditions in older adults with balance impairment. Phys Ther 2006;86:269-281. 